\title{
Epidermal growth factor receptor somatic mutation analysis in 354 Chinese patients with non-small cell lung cancer
}

\author{
XUEPING QUAN $^{1 *}$, HONGJUN GAO ${ }^{2 *}$, ZHIKUAN WANG $^{3 *}$, JIE LI $^{4 *}$, WENTAO ZHAO ${ }^{1}$, \\ WEI LIANG ${ }^{1}$, QIANG YU ${ }^{1}$, DONGLIANG GUO ${ }^{1}$, ZHANPING HAO ${ }^{1}$ and JINGXIN LIU ${ }^{5}$ \\ ${ }^{1}$ Vishuo MedTech Ltd., Beijing 100070; ${ }^{2}$ Department of Lung Cancer, Affiliated Hospital of \\ Academy of Military Medical Sciences, Beijing 100071; Departments of ${ }^{3}$ Medical Oncology and ${ }^{4}$ Thoracic Surgery, \\ General Hospital of The Chinese People's Liberation Army, Beijing 100853; ${ }^{5}$ Department of Medical Engineering, \\ China-Japan Union Hospital of Jilin University, Changchun, Jilin 130033, P.R. China
}

Received June 27, 2017; Accepted October 26, 2017

DOI: $10.3892 / \mathrm{ol} .2017 .7622$

\begin{abstract}
Lung cancer is one of the most common types of cancer worldwide, with the highest mortality rate of all types of cancer. In the present study, epidermal growth factor receptor (EGFR) mutations of 354 primary patients with non-small cell lung cancer (NSCLC) of Chinese ethnicity were detected following formalin-fixed and paraffin-embedded specimen DNA extraction, polymerase chain reaction amplification, and sanger sequencing. The total rate of occurrence of EGFR somatic mutation in these 354 patients was $48.02 \%$. Of these detected EGFR mutations, 27.40\% were located in exon 19 and $25.99 \%$ in exon 21 . The most frequent mutation in exon 19 was E746-A750del (8.47\%), and in exon 21, L858R (10.17\%). EGFR mutation rates were significantly associated with sex [female vs. male: 60.13 vs. $38.81 \%$; adjusted odds ratio (OR), 1.93, $95 \%$ confidence interval $(\mathrm{CI}), 1.07-3.51, \mathrm{P}=0.029$ ], age ( $<60$ vs. $\geq 60 ; 58.62$ vs. $40.67 \%$; adjusted OR, 1.87; 95\% CI, 1.20-2.92; $\mathrm{P}=0.006$ ) and histology [adenocarcinoma (ADC) vs. non-ADC; 52.76 vs. $26.56 \%$; adjusted OR, 2.35; 95\% CI, 1.28-4.50; $\mathrm{P}=0.007]$. The frequency of E746_A750del, Q787Q and L858R mutations were significantly different in ADC patients compared with squamous cell carcinoma patients $(\mathrm{P}<0.001)$. Furthermore, a novel EGFR mutation, M793K, was detected in 7 NSCLC patients with possible gefitinib resistance. The
\end{abstract}

Correspondence to: Dr Xueping Quan, Vishuo MedTech Ltd., 8th Floor, Wanrun Building, 1 Haiyung Road, Fengtai, Beijing 100070, P.R. China

E-mail: xueping.quan@vishuo.co

Professor Jingxin Liu, Department of Medical Engineering, China-Japan Union Hospital of Jilin University, 126 Xiantai Street, Changchun, Jilin 130033, P.R. China

E-mail: liujingxin@126.com

*Contributed equally

Key words: epidermal growth factor receptor, somatic mutation, non-small cell lung cancer present study analyzed the EGFR exon 18-21 mutation occurrence profile for Chinese patients with NSCLC and identified significant associations between different EGFR mutations with demographic and histological factors. These results may offer clinical benefits and potential novel treatments.

\section{Introduction}

Lung cancer is the most frequent type of primary cancer for men in China, and it has the highest mortality rate for any type of cancer worldwide (1). Despite the lower incidence of lung cancer than breast cancer for women, its mortality rate is also the highest for women (2). There are three major types of lung cancer, including non-small cell lung cancer (NSCLC), small cell lung cancer and carcinoid lung cancer. NSCLC is the most common type of lung cancer, accounting for $85 \%$ of all lung cancer cases. NSCLC can be further divided into three major histological subtypes: Adenocarcinoma (ADC), squamous cell carcinoma (SCC) and large cell carcinoma ( LCC) $(3,4)$. Patients with lung cancer do not always present distinct symptoms, and are commonly diagnosed at an advanced stage or after the primary cancer has metastasized. This causes a poor prognosis and high mortality rate for patients with lung cancer (4). The prevention and treatment of lung cancer urgently requires improvement through further understanding the molecular origins and development of the disease.

An increased exposure to smoking is associated with an increased risk of developing NSCLC (5,6). However, only 10-24\% of smokers develop NSCLC, indicating that other environmental and genetic factors also contribute to NSCLC development $(7,8)$. Mutations in the epidermal growth factor receptor (EGFR) gene are common in NSCLC patients, with mutation rates differing in males, females, smokers and non-smokers $(9,10)$. EGFR mutations affect the EGF-EGFR-RAS-RAF signaling pathway, and are usually driver mutations for NSCLC development (11). EGFR is, therefore, one of the most important targets in NSCLC treatment. Small molecule tyrosine kinase inhibitors (TKIs) that target EGFR, including gefitinib and erlotinib, have significantly improved the overall survival rate of patients with EGFR-activating mutations. The efficacy of TKI drugs differs depending on the region of the EGFR kinase domain in which 
the mutation is located $(12,13)$. Among the NSCLC patients with EGFR mutations, the overall response rate for treatment with gefitinib is $\sim 75 \%$, with a progression-free survival time of 9-13 months (14). Despite their low prevalence, new targetable EGFR mutations may improve the treatment and elongate the overall survival rate of patients with NSCLC.

In this study, EGFR mutations were detected in 354 patients with NSCLC of Chinese ethnicity by sequencing exons 18-21 from tumor samples. Further analysis was performed to determine the association between EGFR mutations and other variables, including age, gender, smoking status, and histology groups. A novel EGFR mutation, M793K, was detected in 7 patients with potential resistance to gefitinib.

\section{Patients and methods}

Patients. A total of 354 patients with NSCLC at the 307 th Hospital of the Chinese People's Liberation Army (Beijing, China) and the General Hospital of the Chinese People's Liberation Army (Beijing, China) were enrolled in this study between November 2012 and April 2016. Informed consent was obtained from all individual participants included in the study, which was approved by the Ethics Committee of the Affiliated Hospital of Academy of Military Medical Sciences and the Ethics Committee of the General Hospital of Chinese People's Liberation Army. Formalin-fixed and paraffin-embedded (FFPE) tumor samples were prepared from primary surgical or biopsy specimens from patient lung tissue. All FFPE tissue specimens were identified by pathologists as primary NSCLC.

Detection of EGFR mutations. Tumor genomic DNA from each FFPE sample was extracted using the ALLPrep DNA/RNA FFPE kit (Qiagen, Inc., Valencia, CA, USA) according to the manufacturer's instructions. The DNA samples were examined for purity and concentration, and were diluted to a working concentration of $10 \mathrm{ng} / \mu \mathrm{l}$. The detection of EGFR mutations was performed using Sanger sequencing with the ABI 3130 genetic analyzer (Applied Biosystems; Thermo Fisher Scientific, Inc., Waltham, MA, USA). The primers used are listed in Table I and were generated according to the manufacturer's protocol (Tianyi Huiyuan LLC, Beijing, China).

Statistical analysis. $\chi^{2}$ tests for univariate analysis were performed to investigate the association between EGFR mutation frequency and clinicopathological features. Associations between EGFR mutation status and sex, age, smoking history and clinicopathological characteristics were further evaluated by multivariate logistic regression analysis. The adjusted odds ratio (OR) and 95\% confidence interval (CI) were then identified. Associations between sex, age, smoking history and pathology with specific mutations were analyzed using an exact binomial test. A two-sided $\mathrm{P}<0.05$ was considered to indicate a statistically significant difference. All statistical analysis was performed using R (version 3.2.3; http://www.r-project.org/).

$3 D$ model protein building and EGFR-gefitinib affinity estimation. The EGFR kinase domain with M793K mutation was constructed using structure 2JIT from the Protein Data Bank (originally the EGFR kinase domain including a T790M mutation; $3.1 \AA$, complete from 696-986) as a template using
Table I. Primers for the detection of EGFR mutations in patients with non-small cell lung cancer.

\begin{tabular}{lc}
\hline Primer name & Primer sequence, 5'-3' \\
\hline EGFR(E18)-F & GAAGCTCCCAACCAAGCTCT \\
EGFR(E18)-R & CTCCCCACCAGACCATGAGA \\
EGFR(E19)-F & TGCCAGTTAACGTCTTCCTTC \\
EGFR(E19)-R & CCCACACAGCAAAGCAGAAA \\
EGFR(E20)-F & CCAGGAAGCCTACGTGATGG \\
EGFR(E20)-R & GACATAGTCCAGGAGGCAGC \\
EGFR(E21)-F & GTGAAAACACCGCAGCATGT \\
EGFR(E21)-R & GCCACCTCCTTACTTTGCCT
\end{tabular}

EGFR, epidermal growth factor receptor; E, exon; F, forward; R, reverse.

Table II. Characteristics of 354 patients with non-small cell lung cancer.

Characteristic

Patients, n (\%)

$\begin{array}{lc}\text { Sex, } \mathrm{n}(\%) & \\ \text { Male } & 201(56.78) \\ \text { Female } & 153(43.22) \\ \text { Age, years } & \\ \geq 60, \mathrm{n}(\%) & 209(59.04) \\ <60, \mathrm{n}(\%) & 145(40.96) \\ \text { Median (range) } & 62(32-92) \\ \text { Smoking status, } \mathrm{n}(\%) & \\ \text { Smokers } & 174(49.15) \\ \text { Non-smokers } & 180(50.85) \\ \text { Histology type, n }(\%) & \\ \text { Adenocarcinoma } & 290(81.92) \\ \text { Squamous cell carcinoma } & 60(16.95) \\ \text { Large cell carcinoma } & 4(1.13)\end{array}$

the SWISS-model server (https://swissmodel.expasy.org/). The structure for wild type EGFR domain was from 1M14 from the Protein Data Bank (2.6 ̊, complete from 672-960). SWISS-DOCK (http://www.swissdock.ch/) was used to test the binding energy of gefitinib (from ZINC; 19632614) to the 3 structures using the CHARMM energy field method.

\section{Results}

Demographic profile of NSCLC patients. The EGFR mutation status was analyzed in 354 NSCLC patients. Of these patients, $43.22 \%$ were female and $56.78 \%$ were male. The patient age ranged from 32-92 years, with a median age of 62 . A total of $59.04 \%$ of the patients were $\geq 60$ years old and $40.96 \%<60$ years old. Of the 354 patients, $50.85 \%$ had never smoked. Pathological analysis revealed that $81.92 \%$ of the samples were from ADC, $16.95 \%$ from SCC, and $1.13 \%$ from LCC (Table II). 
Table III. Summary of epidermal growth factor receptor exon 18-21 mutations in 354 non-small cell lung cancer tissue samples.

\section{8}

18

18

18

18

18

18

18

18

18

18

18

18

18

18

18

18

18

18

18

18

18

18

18

18

18

18

18

18

18

19

19

19

19

19

19

19

19

19

19

19

19

19

19

19

19

19

19

19

19

\begin{tabular}{ll}
\hline Exon & Mutation
\end{tabular}

18.

V689M

P691S

P694L

Q701L

Q701R

Q701X

L703P

R705G

L707S

K708E

K708R

E709_710T $>$ D

E709K

E711A

E711V

F712L

F712Q

K713H

I715V

V717A

G719A

G719D

G719V

S720P

S720T

G721S

F723C

F723L

K728M

K728T

L730I

I732V

E734A

E734R

G735D

E736V

K737R

V738L

I740F

P741R

P741S

V742A

I744V

K745R

E746_A750del

E746_E749del

E746_S752>A

E746_S752>D

E746_T751>A

E746_T751del

$\begin{array}{ll}0.28 & 19\end{array}$

$0.28 \quad 19$

$0.28 \quad 19$

$0.56 \quad 19$

$0.28 \quad 19$

$0.28 \quad 19$

$0.28 \quad 19$

$0.56 \quad 19$

$0.56 \quad 19$

$0.56 \quad 19$

$0.28 \quad 19$

$0.28 \quad 19$

$0.28 \quad 19$

$0.28 \quad 19$

$0.28 \quad 19$

$0.28 \quad 19$

$0.28 \quad 20$

$0.56 \quad 20$

$0.56 \quad 20$

$0.28 \quad 20$

$0.28 \quad 20$

$0.28 \quad 20$

$0.28 \quad 20$

$0.56 \quad 20$

$0.28 \quad 20$

$0.28 \quad 20$

$0.28 \quad 20$

$0.56 \quad 20$

$0.28 \quad 20$

$0.28 \quad 20$

$1.13 \quad 20$

$0.28 \quad 20$

$0.28 \quad 20$

$0.85 \quad 20$

$0.28 \quad 20$

$0.28 \quad 20$

$0.28 \quad 20$

$0.28 \quad 20$

$0.28 \quad 20$

$0.28 \quad 20$

$0.28 \quad 20$

$0.56 \quad 20$

$0.28 \quad 20$

$0.28 \quad 20$

$8.47 \quad 20$

$0.28 \quad 20$

$0.28 \quad 20$

$0.56 \quad 20$

$1.69 \quad 20$

$0.28 \quad 20$
Mutation

Frequency (\%)

E746K
L747_750A >S
L747_A750de
L747_E749del
L747_P753>S
L747_T751del
R748G
E749G
S752_I759del
P753T
K754R

0.56

0.28

0.85

0.56

1.98

1.13

0.28

0.28

0.85

0.28

0.28

$\mathrm{A} 755 \mathrm{~V} \quad 0.28$

K757E $\quad 0.28$

K757T 0.28

E758K $\quad 0.28$

L760P $\quad 0.85$

$\mathrm{D} 761 \mathrm{H} \quad 0.28$

D761Q $\quad 0.56$

A763T $\quad 0.28$

V765A $\quad 0.28$

A767S $\quad 0.28$

A767V $\quad 0.28$

S768_V769insGGQ 0.28

S768I $\quad 0.28$

S768R $\quad 0.28$

D770_N771insG $\quad 0.28$

D770_N771insTP $\quad 0.28$

$\mathrm{N} 771>\mathrm{KT} \quad 0.28$

C775Y 0.28

R776A 0.28

$\mathrm{R} 776 \mathrm{H} \quad 0.28$

L777C $\quad 0.28$

L777P $\quad 0.28$

L778Q $\quad 0.28$

G779D $\quad 0.28$

I780S $\quad 0.28$

$\begin{array}{ll}\mathrm{T} 783 \mathrm{~A} & 0.28\end{array}$

S784P $\quad 0.28$

V786A $\quad 0.28$

Q787Q $\quad 3.11$

L788Q $\quad 0.28$

$\mathrm{I789F} \quad 0.28$

T790M 1.13

Q791L $\quad 0.28$

M793K $\quad 1.98$

M793L $\quad 0.28$

P794L 0.28

F795L $\quad 0.56$

C797S 0.28

L799Q $\quad 1.41$

$\begin{array}{ll}\mathrm{V} 802 \mathrm{~A} & 0.28\end{array}$

L814M 0.28 
Table III. Continued.

\begin{tabular}{|c|c|c|}
\hline Exon & Mutation & Frequency (\%) \\
\hline 21 & M825T & 0.28 \\
\hline 21 & $\mathrm{~N} 826 \mathrm{H}$ & 0.28 \\
\hline 21 & $\mathrm{~N} 826 \mathrm{~S}$ & 0.28 \\
\hline 21 & E829D & 0.28 \\
\hline 21 & V834A & 0.56 \\
\hline 21 & V834M & 0.28 \\
\hline 21 & $\mathrm{R} 836 \mathrm{H}$ & 0.28 \\
\hline 21 & A840T & 0.28 \\
\hline 21 & V845A & 0.28 \\
\hline 21 & K846I & 1.13 \\
\hline 21 & Q849L & 0.28 \\
\hline 21 & Q849R & 0.28 \\
\hline 21 & $\mathrm{H} 850 \mathrm{Y}$ & 0.28 \\
\hline 21 & $\mathrm{I} 853 \mathrm{~T}$ & 0.28 \\
\hline 21 & $\mathrm{~T} 854 \mathrm{~A}$ & 0.28 \\
\hline 21 & D855A & 0.28 \\
\hline 21 & F856L & 1.13 \\
\hline 21 & G857E & 0.28 \\
\hline 21 & G857W & 0.56 \\
\hline 21 & $\mathrm{~L} 858 \mathrm{H}$ & 0.28 \\
\hline 21 & L858P & 0.28 \\
\hline 21 & L858R & 10.17 \\
\hline 21 & K860R & 0.28 \\
\hline 21 & K860Tfs & 0.28 \\
\hline 21 & L861Q & 0.56 \\
\hline 21 & L862Q & 0.28 \\
\hline 21 & G863C & 0.28 \\
\hline 21 & G863S & 0.28 \\
\hline 21 & G863V & 0.28 \\
\hline 21 & $\mathrm{E} 865 \mathrm{G}$ & 0.28 \\
\hline 21 & E865K & 0.56 \\
\hline 21 & E866G & 0.28 \\
\hline 21 & E866R & 0.56 \\
\hline 21 & E866X & 0.28 \\
\hline 21 & K867D & 0.28 \\
\hline 21 & K867I & 0.28 \\
\hline 21 & K867N & 0.85 \\
\hline 21 & E868D & 0.28 \\
\hline 21 & E868V & 0.28 \\
\hline 21 & H870Q & 0.28 \\
\hline 21 & H870R & 0.28 \\
\hline 21 & A871T & 0.28 \\
\hline 21 & A871V & 0.28 \\
\hline 21 & G873E & 0.28 \\
\hline
\end{tabular}

EGFR mutation distributions. EGFR mutations were identified in $48.02 \%$ (170) patients, with a single mutation identified in the majority of these patients (121 out of 170, 71.18\%). Patients with more than one EGFR mutation were relatively uncommon: $13.53 \%$ (23/170) exhibited double mutations, 6.74\% (11/170) triple mutations, $2.94 \%$ (5/170) quadruple mutations, $1.76 \%$
(2/170) quintuple mutations, $1.76 \%$ (3/170) sextuple mutations, $1.18 \%(2 / 170)$ septuple mutations and 1.18\% (3/170) nonuple mutations. Of the 170 patients with EGFR mutations, 97 patients had point mutations in exon 19 and 92 in exon 21. The remaining mutations were located in exon 20 (58 patients) and exon 18 (38 patients). The most common mutation in exon 19 was E746-A750del (30 patients), and the most common in exon 21 was L858R (36 patients). In exon 20, Q787Q and M793K were detected in 11 and 7 patients, respectively (Table III).

Associations between EGFR mutation occurrence and clinicopathological features. Patients were divided into two groups (with and without EGFR mutations) for clinicopathological feature association analysis (Fig. 1). Multivariate logistic regression analysis revealed that EGFR mutations were more frequently detected in females than in males (female vs. male; 60.13 vs. $38.81 \%$; adjusted OR, 1.93; 95\% CI, 1.07-3.51; $\mathrm{P}=0.029)$. Patients $\geq 60$ were more likely to have EGFR mutations than patients $<60$ years old ( $<60$ vs. $\geq 60 ; 58.62$ vs. 40.67\%; adjusted OR, 1.87; 95\% CI, 1.20-2.92; $\mathrm{P}=0.006)$. ADC patients had a higher chance of exhibiting EGFR mutations than non-ADC patients (ADC vs. non-ADC; 52.76 vs. 26.56\%; adjusted $\mathrm{OR}, 2.35 ; 95 \% \mathrm{CI}, 1.28-4.50 ; \mathrm{P}=0.007)$. There was no significant difference between smokers and non-smokers in the EGFR mutation rate (smokers vs. non-smokers; 55.56 vs. 40.23\%; adjusted OR, 1.02; 95\% CI, 0.56-1.82; $\mathrm{P}=0.952$ ). However, if only patients $<60$ are considered, EGFR mutation rate in non-smokers was significantly higher than in smokers (non-smokers vs. smokers; 66.27 vs. 48.39\%; adjusted OR, 2.10; 95\% CI, 1.07-4.11; P=0.046). Similar results were identified between non-smokers and smokers with ADC (non-smokers with ADC vs. smokers with ADC; 58.64 vs. 45.31\%; adjusted OR, 1.71; 95\% CI, 1.07-2.73; $\mathrm{P}=0.032$; Table IV).

Association between specific mutations and clinicopathological features. The association between specific mutations and clinicopathological features was analyzed using an exact binomial test. Between patients with ADC and SCC, the frequencies of E746_A750del, Q787Q and L858R mutations were significantly different $(\mathrm{P}<0.001)$. Furthermore, the L858R mutation was significantly more frequent in smokers than in non-smokers. No significant associations were identified between specific mutations and other clinicopathological features (Fig. 1).

Analysis of the M793K mutation. The EGFR mutation M793K was detected in 7 out of 354 patients with NSCLC, including five smokers. No KRAS mutations or EGFR drug-resistance mutations, including T790M or C797S, were detected in these 7 patients. However, the follow-up information for these patients demonstrated that they responded poorly to treatment with gefitinib. Similar to the T790M mutation, M793K also occurs in the inhibitor-binding cleft between the N-lobe and C-lobe of the EGFR kinase domain, indicating that it is likely to be a novel drug-resistance mutation.

Gefitinib was always identified in the cleft between the $\mathrm{N}$-lobe and C-lobe in the 3D models of wild type EGFR, EGFR with T790M and EGFR with M793K (Fig. 2). A total of 256 binding poses for wild type EGFR, 256 for EGFR with T790M and 252 for EGFR with M793K were determined. 
A
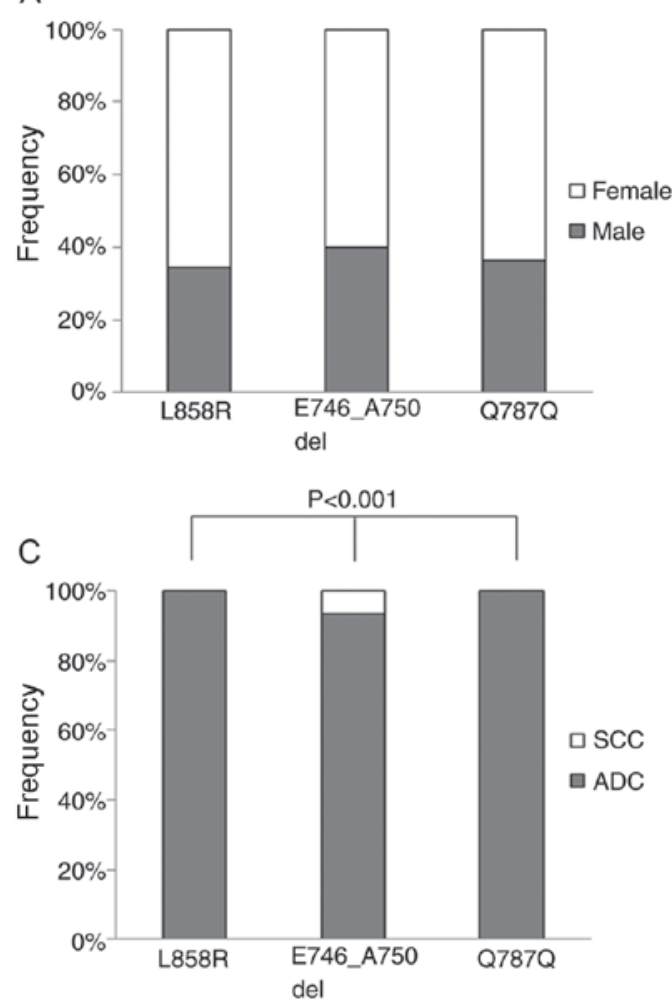

B
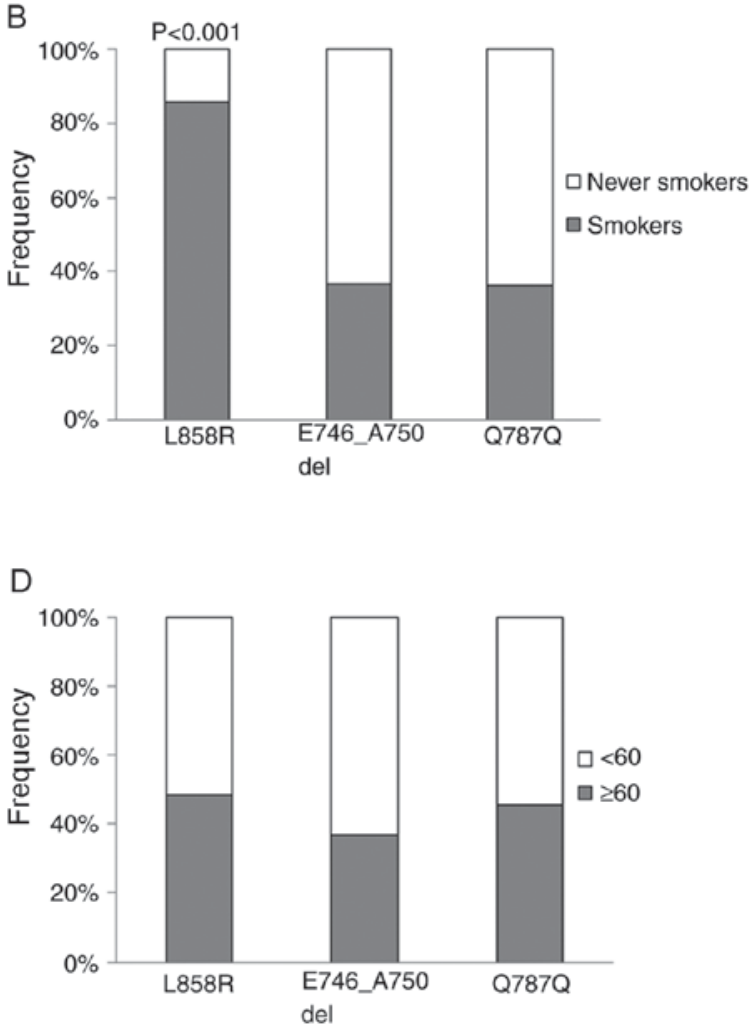

Figure 1. Analysis of the statistical associations between specific mutations and clinicopathological features. Association of mutations with (A) sex, (B) smoking status, (C) cancer type and (D) age.

A

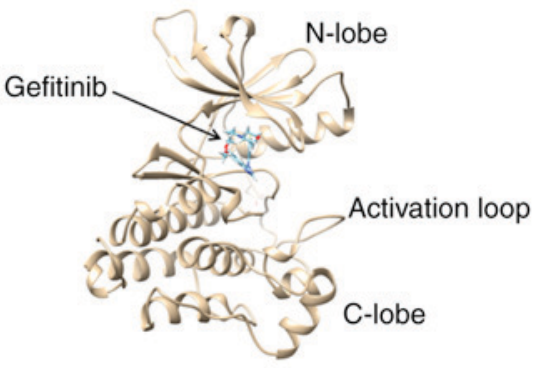

B

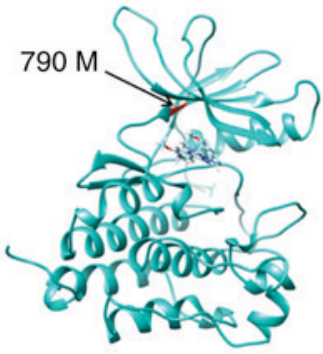

C

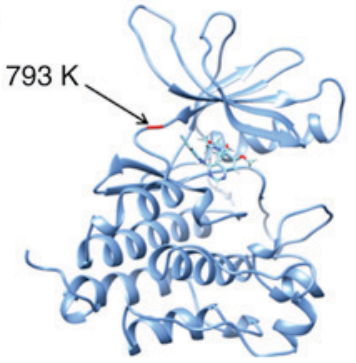

Figure 2. 3D models of (A) the wild type EGFR kinase domain, (B) the EGFR kinase domain with a T790M mutation and (C) the EGFR kinase domain with an M793K mutation. EGFR, epidermal growth factor receptor.

The full fitness scores between gefitinib and EGFR ranged from -2196.87 to $-2160.79 \mathrm{kcal} / \mathrm{mol}$ for wild type EGFR, from -1791.71 to $-1756.65 \mathrm{kcal} / \mathrm{mol}$ for M793K-mutated EGFR, and from -1805.53 to- $1759.77 \mathrm{kcal} / \mathrm{mol}$ for T790M-mutated EGFR (Table V). The reduced affinity between gefitinib and EGFR with M793K may be reflective of the gefitinib drug resistance of patients with M793K.

\section{Discussion}

EGFR mutations were detected in 170 out of the 354 patients with NSCLC of Chinese ethnicity by Sanger sequencing of EGFR exons 18-21. Associations between EGFR mutation occurrence and patient clinicopathological factors were further analyzed. A new EGFR mutation, M793K, was detected and predicted to be a TKI resistance mutation.

Of the 354 NSCLC patients, $43.22 \%$ were female and $56.78 \%$ were male, $50.85 \%$ patients were non-smokers and $49.15 \%$ were smokers. Pathological slides were collected and diagnosed for all patients, with $81.92 \%$ samples identified as ADCs, $16.95 \%$ as SCCs and $1.13 \%$ as LCCs. It is generally accepted that the median age of patients with NSCLC worldwide is 71 (15). The lower median age in this study (62 years), supports the indication that the median age of patients with NSCLC in Asia has lowered $(9,16,17)$.

Less than 30\% patients had multiple EGFR mutations in the present study. The most common mutations were L858R (36 patients) and E746-A750del (30 patients), which is consistent with previous reports $(9,10)$. Multivariate logistic regression analysis revealed that EGFR mutations happened more frequently in females $(\mathrm{P}=0.029)$, older patients $(\geq 60$ years old; $\mathrm{P}=0.006)$ and ADC $(\mathrm{P}=0.007)$, which consolidates the results of previous reports (18-21). There was no significant difference in the EGFR mutation rate between smokers and non-smokers $(\mathrm{P}=0.952)$. However, in patients $<60$ years old, univariate analysis revealed that non-smokers are much more likely to have EGFR mutations than smokers $(\mathrm{P}=0.046)$. This was also true for patients with $\mathrm{ADC}$, whereas non-smokers exhibited a higherEGFR mutation rate than smokers $(\mathrm{P}=0.032)$. 
Table IV. Association of EGFR mutations with the clinicopathological features of patients with non-small cell lung cancer.

\begin{tabular}{|c|c|c|c|c|c|c|}
\hline \multirow[b]{2}{*}{ Variable } & \multicolumn{2}{|c|}{ EGFR status, $\mathrm{n}$} & \multicolumn{2}{|l|}{ Univariate } & \multicolumn{2}{|l|}{ Multivariate } \\
\hline & Mutant & Wild type & Crude OR (95\% CI) & P-value & Adjusted OR (95\% CI) & P-value \\
\hline \multicolumn{7}{|l|}{ Sex } \\
\hline Male & 78 & 123 & Ref. & & Ref. & \\
\hline Female & 92 & 61 & $2.378(1.547-3.657)$ & $<0.001$ & $1.929(1.072-3.506)$ & 0.029 \\
\hline \multicolumn{7}{|l|}{ Age, years } \\
\hline$\geq 60$ & 85 & 124 & Ref. & & Ref. & \\
\hline$<60$ & 85 & 60 & $2.067(1.344-3.179)$ & 0.001 & $1.869(1.200-2.923)$ & 0.006 \\
\hline \multicolumn{7}{|l|}{ Smoking status } \\
\hline Smoker & 70 & 104 & Ref. & & Ref. & \\
\hline Non-smoker & 100 & 80 & $1.857(1.218-2.833)$ & 0.005 & $1.018(0.564-1.815)$ & 0.952 \\
\hline \multicolumn{7}{|l|}{ Pathology } \\
\hline Non-ADC & 17 & 47 & Ref. & & Ref. & \\
\hline $\mathrm{ADC}$ & 153 & 137 & $3.088(1.693-5.630)$ & $<0.001$ & $2.352(1.275-4.497)$ & 0.007 \\
\hline \multicolumn{7}{|l|}{ Smokers } \\
\hline Male & 63 & 94 & Ref. & & & \\
\hline Female & 7 & 10 & $1.044(0.378-2.888)$ & 1 & & \\
\hline \multicolumn{7}{|l|}{ Non-smokers } \\
\hline Male & 15 & 29 & Ref. & & & \\
\hline Female & 85 & 51 & $3.222(1.579-6.577)$ & 0.002 & & \\
\hline \multicolumn{7}{|l|}{$\mathrm{ADC}$} \\
\hline Male & 65 & 82 & Ref. & & & \\
\hline Female & 88 & 55 & $2.019(1.264-3.225)$ & 0.005 & & \\
\hline \multicolumn{7}{|l|}{$\mathrm{SCC}$} \\
\hline Male & 12 & 38 & Ref. & & & \\
\hline Female & 4 & 6 & $2.111(0.509-8.751)$ & 0.514 & & \\
\hline \multicolumn{7}{|c|}{ Non-smokers with ADC } \\
\hline Male & 14 & 20 & Ref. & & & \\
\hline Female & 81 & 47 & $2.462(1.138-5.327)$ & 0.033 & & \\
\hline \multicolumn{7}{|l|}{ Male } \\
\hline Smokers & 63 & 94 & Ref. & & & \\
\hline Non-smokers & 15 & 29 & $0.772(0.383-1.555)$ & 0.582 & & \\
\hline \multicolumn{7}{|l|}{ Female } \\
\hline Smokers & 7 & 10 & Ref. & & & \\
\hline Non-smokers & 85 & 51 & $2.381(0.853-6.645)$ & 0.153 & & \\
\hline \multicolumn{7}{|l|}{$\geq 60$} \\
\hline Smokers & 40 & 72 & Ref. & & & \\
\hline Non-smokers & 45 & 52 & $1.558(0.894-2.715)$ & 0.154 & & \\
\hline \multicolumn{7}{|l|}{$<60$} \\
\hline Smokers & 30 & 32 & Ref. & & & \\
\hline Non-smokers & 55 & 28 & $2.096(1.067-4.114)$ & 0.046 & & \\
\hline \multicolumn{7}{|l|}{$\mathrm{ADC}$} \\
\hline Smokers & 58 & 70 & Ref. & & & \\
\hline Non-smokers & 95 & 67 & $1.711(1.072-2.732)$ & 0.032 & & \\
\hline \multicolumn{7}{|l|}{ SCC } \\
\hline Smokers & 11 & 31 & Ref. & & & \\
\hline Non-smokers & 5 & 13 & $1.084(0.314-3.745)$ & 1 & & \\
\hline \multicolumn{7}{|l|}{ Males with ADC } \\
\hline Smokers & 51 & 62 & Ref. & & & \\
\hline Non-smokers & 14 & 20 & $0.851(0.391-1.851)$ & 0.833 & & \\
\hline
\end{tabular}


Table IV. Continued.

\begin{tabular}{|c|c|c|c|c|c|c|}
\hline \multirow[b]{2}{*}{ Variable } & \multicolumn{2}{|c|}{ EGFR status, $\mathrm{n}$} & \multicolumn{2}{|l|}{ Univariate } & \multicolumn{2}{|l|}{ Multivariate } \\
\hline & Mutant & Wild type & Crude OR (95\% CI) & P-value & Adjusted OR (95\% CI) & P-value \\
\hline \multicolumn{7}{|c|}{ Females with ADC } \\
\hline Smokers & 7 & 8 & Ref. & & & \\
\hline Non-smokers & 81 & 47 & $1.970(0.671-5.778)$ & 0.331 & & \\
\hline \multicolumn{7}{|l|}{$\geq 60$ male } \\
\hline Smokers & 36 & 63 & Ref. & & & \\
\hline Non-smokers & 7 & 22 & $0.557(0.217-1.431)$ & 0.316 & & \\
\hline \multicolumn{7}{|l|}{$<60$ female } \\
\hline Smokers & 3 & 1 & Ref. & & & \\
\hline Non-smokers & 47 & 21 & $0.746(0.073-7.598)$ & 1 & & \\
\hline \multicolumn{7}{|l|}{$\geq 60 \mathrm{ADC}$} \\
\hline Smokers & 33 & 45 & Ref. & & & \\
\hline Non-smokers & 43 & 43 & $1.364(0.736-2.527)$ & 0.407 & & \\
\hline \multicolumn{7}{|l|}{$<60 \mathrm{ADC}$} \\
\hline Smokers & 25 & 25 & Ref. & & & \\
\hline Non-smokers & 52 & 24 & $2.167(1.038-4.522)$ & 0.059 & & \\
\hline
\end{tabular}

EGFR, epidermal growth factor receptor; OR, odds ratio; CI, confidence interval; Ref., reference value; ADC, adenocarcinoma; SCC, squamous cell carcinoma.

Table V. Full fitness score between gefitinib and EGFR wild type and EGFR T790M and M793K mutants, as predicted by Swiss-Dock.

\begin{tabular}{lc}
\hline EGFR & Full fitness score $(\mathrm{kcal} / \mathrm{mol})$ \\
\hline Wild type & $(-2,196.87 ;-2,160.79)$ \\
T790M & $(-1,805.53 ;-1,759.77)$ \\
M793K & $(-1,791.71 ;-1,756.65)$ \\
\hline
\end{tabular}

EGFR, epidermal growth factor receptor.

A significant association was observed between histology type and specific EGFR mutation rates as the frequencies of E746_A750del, Q787Q and L858R mutations were significantly different between patients with ADC and patients with SCC $(\mathrm{P}<0.001)$. Smokers were also more likely to have the L858R mutation than non-smokers.

The EGFR gene encodes a receptor protein that dimerizes upon ligand binding, activating tyrosine kinase activity and receptor phosphorylation. The kinase activity of EGFR can be increased by mutations to EGFR, inducing the hyperactivation of downstream pro-survival signaling pathways (22). Initial studies on the TKIs gefitinib (Iressa) and erlotinib (Tarceva) demonstrated biological and clinical significance in a subset of lung cancers (23). Further investigation demonstrated that patients with advanced NSCLC and EGFR-activating mutations (particularly exon 19 deletions, L858R in exon 21, and G719X in exon 18) demonstrated the highest response rates to these TKIs (24). However, over 6-12 months of treatment, the majority of tumor cells gained resistance to EGFR-TKIs through a secondary mutation. Previous studies reported that T790M occurs in $50 \%$ of EGFR-mutated patients with TKI resistance $(25,26)$ and it is considered a TKI acquired resistance mutation (27-29). In this study, a new mutation, M793K, was detected in 7 out of 354 NSCLC patients. These 7 patients gained drug resistance following their treatment with gefitinib, and no other previously identified drug resistance mutations were detected in these patients.

The docking analysis of gefitinib and EGFR kinase domain with/without T790M or M793K mutations demonstrated that gefitinib was always identified in the cleft between the $\mathrm{N}$-lobe and C-lobe of the EGFR kinase domain, which is also the location of M793K. TKIs form direct H-bonds with M793 and T790 (30-33). Computational simulation and prediction methodologies have predicted that M793 forms a high proportion of these H-bonds with inhibitors (34) and M793K was previously predicted to be associated with drug resistance (resistance score, 0.057) (35). The full fitness score between gefitinib and the EGFR M793K structure was higher than that between gefitinib and the wild type EGFR structure, and between gefitinib and the EGFR T790M structure. These findings indicate that M793K reduces the binding affinity between gefitinib and EGFR and may induce the development of the resistance to TKI treatment.

In coclusion, the present study presents a complete picture of exon 18-21 EGFR mutations based on 354 Chinese patients with NSCLC, and investigates the association between EGFR mutations with sex, age, smoking history, and histology. The EGFR M793K mutation was identified for the first time in NSCLC patients and may have been associated with resistance to TKI treatment. This finding laid the basis for the further investigation of the association between M793K mutation and TKI treatment clinical outcomes. 


\section{Acknowledgements}

The authors wish to thank Mr. Jinglei Bi (Vishuo MedTech Ltd., Beijing, China) and Dr Dianyun Wu (Vishuo MedTech Ltd.) for their technical assistance. The present study was financially supported by Vishuo MedTech Ltd.

\section{References}

1. Jemal A, Bray F, Center MM, Ferlay J, Ward E and Forman D: Global cancer statistics. CA Cancer J Clin 61: 69-90, 2011.

2. Chen W, Zheng R, Baade PD, Zhang S, Zeng H, Bray F, Jemal A, Yu XQ and He J: Cancer statistics in China, 2015. CA Cancer J Clin 66: 115-132, 2016.

3. Travis WD, Brambilla E, Nicholson AG, Yatabe Y, Austin JHM, Beasley MB, Chirieac LR, Dacic S, Duhig E, Flieder DB, et al: The 2015 world health organization classification of lung tumors: Impact of genetic, clinical and radiologic advances since the 2004 classification. J Thorac Oncol 10: 1243-1260, 2015.

4. Herbst RS, Heymach JV and Lippman SM: Lung cancer. N Engl J Med 359: 1367-1380, 2008.

5. Hecht SS: Tobacco carcinogens, their biomarkers and tobacco-induced cancer. Nat Rev Cancer 3: 733-744, 2003.

6. Thun MJ, Hannan LM, Adams-Campbell LL, Boffetta P, Buring JE, Feskanich D, Flanders WD, Jee SH, Katanoda K, Kolonel LN, et al: Lung cancer occurrence in never-smokers: An analysis of 13 cohorts and 22 cancer registry studies. PLoS Med 5: e185, 2008.

7. Thun MJ, Henley SJ and Calle EE: Tobacco use and cancer: An epidemiologic perspective for geneticists. Oncogene 21: 7307-7325, 2002 .

8. Sun S, Schiller JH and Gazdar AF: Lung cancer in never smokers-a different disease. Nat Rev Cancer 7: 778-790, 2007.

9. Li S, Li L, Zhu Y, Huang C, Qin Y, Liu H, Ren-Heidenreich L, Shi B, Ren H, Chu X, et al: Coexistence of EGFR with KRAS, or BRAF, or PIK3CA somatic mutations in lung cancer: A comprehensive mutation profiling from 5125 Chinese cohorts. $\mathrm{Br}$ J Cancer 110: 2812-2820, 2014.

10. Cai X, Sheng J, Tang C, Nandakumar V, Ye H, Ji H, Tang H, Qin Y, Guan H, Lou F, et al: Frequent mutations in EGFR, KRAS and TP53 genes in human lung cancer tumors detected by ion torrent DNA sequencing. PLoS One 9: e95228, 2014.

11. Wang Y, Wang $M$, Wang Q, Geng Z and Sun M: Incidence and risk of infections associated with EGFR-TKIs in advanced non-small-cell lung cancer: A systematic review and meta-analysis of randomized controlled trials. Oncotarget 8: 29406-29415, 2017.

12. Pao W, Miller V, Zakowski M, Doherty J, Politi K, Sarkaria I, Singh B, Heelan R, Rusch V, Fulton L, et al: EGF receptor gene mutations are common in lung cancers from 'never smokers' and are associated with sensitivity of tumors to gefitinib and erlotinib. Proc Natl Acad Sci USA 101: 13306-13311, 2004

13. Toyooka S, Kiura K and Mitsudomi T: EGFR mutation and response of lung cancer to gefitinib. N Engl J Med 352: 2136, 2005.

14. Mitsudomi T,Morita S, Yatabe Y,NegoroS,OkamotoI, Tsurutani J, Seto T, Satouchi M, Tada H, Hirashima T, et al: Gefitinib versus cisplatin plus docetaxel in patients with non-small-cell lung cancer harbouring mutations of the epidermal growth factor receptor (WJTOG3405): An open label, randomised phase 3 trial. Lancet Oncol 11: 121-128, 2010.

15. Subramanian J, Morgensztern D, Goodgame B, Baggstrom MQ, Gao F, Piccirillo J and Govindan R: Distinctive characteristics of non-small cell lung cancer (NSCLC) in the young: A surveillance, epidemiology, and end results (SEER) analysis. J Thorac Oncol 5: 23-28, 2010

16. Xu J, He J, Yang H, Luo X, Liang Z, Chen J, Cai Z, Xu J and Ren-Heidenreich L: Somatic mutation analysis of EGFR, KRAS, BRAF and PIK3CA in 861 patients with non-small cell lung cancer. Cancer Biomark 10: 63-69, 2011.

17. Zhang L, Yang H, Zhao Y, Liu W, Wu S, He J, Luo X, Zhu Z, $\mathrm{Xu}$ J, Zhou Q and Ren-Heidenreich L: Detection of EGFR somatic mutations in non-small cell lung cancer (NSCLC) using a novel mutant-enriched liquidchip (MEL) technology. Curr Drug Metab 13: 1007-1011, 2012.
18. Kim TJ, Park CK, Yeo CD, Park K, Rhee CK, Kim J, Kim SJ, Lee SH, Lee KY and Yoon HK: Simultaneous diagnostic platform of genotyping EGFR, KRAS, and ALK in 510 Korean patients with non-small-cell lung cancer highlights significantly higher ALK rearrangement rate in advanced stage. J Surg Oncol 110: $245-251,2014$

19. Tokumo M, Toyooka S, Kiura K, Shigematsu H, Tomii K, Aoe M, Ichimura K, Tsuda T, Yano M, Tsukuda K, et al: The relationship between epidermal grow th factor receptor mutations and clinicopathologic features in non-small cell lung cancers. Clin Cancer Res 11: 1167-1173, 2005.

20. Sahoo R, Harini V, Babu V, Patil Okaly GV, Rao S, Nargund A, Venkataswamy E, Rao R and Kumar BS: Screening for EGFR mutations in lung cancer, a report from India. Lung Cancer 73: 316-319, 2011.

21. Xie G, Xie F, Wu P, Yuan X, Ma Y, Xu Y, Li L, Xu L, Yang M and Shen L: The mutation rates of EGFR in non-small cell lung cancer and KRAS in colorectal cancer of Chinese patients as detected by pyrosequencing using a novel dispensation order. J Exp Clin Cancer Res 34: 63, 2015.

22. Ullrich A and Schlessinger J: Signal transduction by receptors with tyrosine kinase activity. Cell 61: 203-212, 1990.

23. Sequist LV, Bell DW, Lynch TJ and Haber DA: Molecular predictors of response toepidermal growth factorreceptorantagonistsinnon-small-cell lung cancer. J Clin Oncol 25: 587-595, 2007.

24. Lynch TJ, Bell DW, Sordella R, Gurubhagavatula S, Okimoto RA, Brannigan BW, Harris PL, Haserlat SM, Supko JG, Haluska FG, et al: Activating mutations in the epidermal growth factor receptor underlying responsiveness of non-small-cell lung cancer to gefitinib. N Engl J Med 350: 2129-2139, 2004.

25. Oxnard GR, Arcila ME, Chmielecki J, Ladanyi M, Miller VA and Pao W: New strategies in overcoming acquired resistance to epidermal growth factor receptor tyrosine kinase inhibitors in lung cancer. Clin Cancer Res 17: 5530-5537, 2011.

26. Ohashi K, Sequist LV, Arcila ME, Moran T, Chmielecki J, Lin YL, Pan Y, Wang L, de Stanchina E, Shien K, et al: Lung cancers with acquired resistance to EGFR inhibitors occasionally harbor BRAF gene mutations but lack mutations in KRAS, NRAS, or MEK1. Proc Natl Acad Sci USA 109: E2127-E2133, 2012.

27. Engelman JA and Jänne PA: Mechanisms of acquired resistance to epidermal growth factor receptor tyrosine kinase inhibitors in non-small cell lung cancer. Clin Cancer Res 14: 2895-2899, 2008.

28. Engelman JA, Mukohara T, Zejnullahu K, Lifshits E, Borrás AM, Gale CM, Naumov GN, Yeap BY, Jarrell E, Sun J, et al: Allelic dilution obscures detection of a biologically significant resistance mutation in EGFR-amplified lung cancer. J Clin Invest 116: 2695-2706, 2006.

29. Tam IY, Leung EL, Tin VP, Chua DT, Sihoe AD, Cheng LC, Chung LP and Wong MP: Double EGFR mutants containing rare EGFR mutant types show reduced in vitro response to gefitinib compared with common activating missense mutations. Mol Cancer Ther 8: 2142-2151, 2009.

30. Stamos J, Sliwkowski MX and Eigenbrot C: Structure of the epidermal growth factor receptor kinase domain alone and in complex with a 4-anilinoquinazoline inhibitor. J Biol Chem 277: 46265-46272, 2002.

31. Michalczyk A, Klüter S, Rode HB, Simard JR, Grütter C, Rabiller M and Rauh D: Structural insights into how irreversible inhibitors can overcome drug resistance in EGFR. Bioorg Med Chem 16: 3482-3488, 2008

32. Cross DA, Ashton SE, Ghiorghiu S, Eberlein C, Nebhan CA, Spitzler PJ, Orme JP, Finlay MR, Ward RA, Mellor MJ, et al: AZD9291, an irreversible EGFR TKI, overcomes T790Mmediated resistance to EGFR inhibitors in lung cancer. Cancer Discov 4: 1046-1061, 2014.

33. Liu B, Bernard B and Wu JH: Impact of EGFR point mutations on the sensitivity to gefitinib: Insights from comparative structural analyses and molecular dynamics simulations. Proteins 65: 331-346, 2006

34. Balius TE and Rizzo RC: Quantitative prediction of fold resistance for inhibitors of EGFR. Biochemistry 48: 8435-8448, 2009.

35. Martínez-Jiménez F, Overington JP, Al-Lazikani B and Marti-Renom MA: Rationally designed drug blending as a mechanism to overcome drug resistance in cancer: An application in EGFR. http://sgt.cnag.cat/www/presentations/files/slides/20150709_Fran Cancer_poster.pdf. Accessed March 27, 2017. 